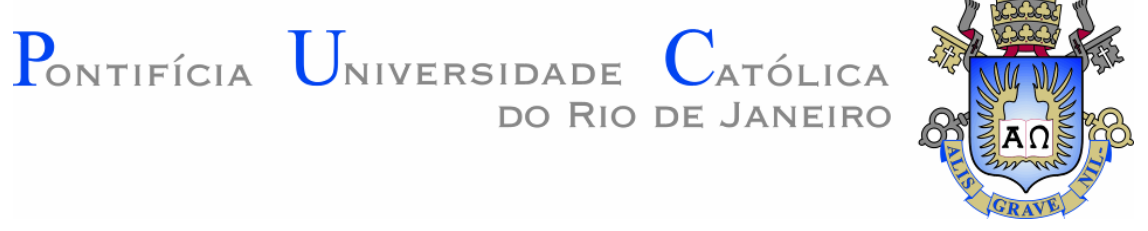

Denis Luis de Oliveira

\begin{abstract}
Avaliação de Projeto de Cogeração a partir de Biomassa Florestal: Uma Abordagem pela Teoria de Opções Reais
\end{abstract}

Dissertação de Mestrado

Dissertação apresentada ao Programa de Pósgraduação em Administração de Empresas da PUCRio como requisito parcial para a obtenção do título de Mestre em Administração de Empresas.

Orientador: Prof. Luiz Eduardo Teixeira Brandão 


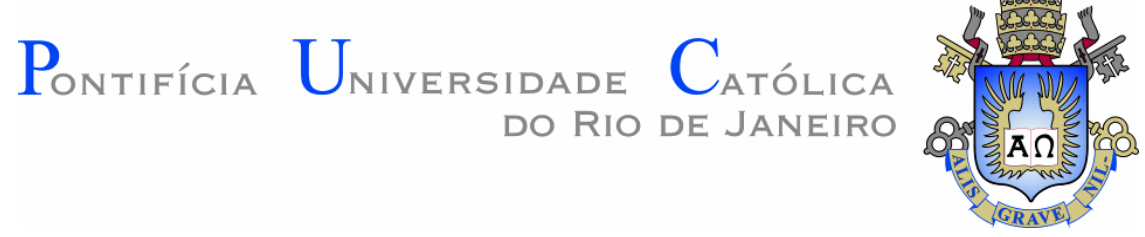

Denis Luis de Oliveira

\section{Avaliação de Projeto de Cogeração a partir de Biomassa Florestal: Uma Abordagem pela Teoria de Opções Reais}

Dissertação apresentada como requisito parcial para obtenção do grau de Mestre pelo Programa de Pósgraduação em Administração de Empresas da PUCRio. Aprovada pela Comissão Examinadora abaixo assinada.

Prof. Luiz Eduardo Teixeira Brandão Orientador Departamento de Administração - PUC-Rio

Prof. Leonardo Lima Gomes Departamento de Administração - PUC-Rio

Prof. Carlos de Lamare Bastian Pinto UNIGRANRIO

Prof $^{\mathrm{a}}$ Fernanda Finotti Cordeiro Perobelli Universidade Federal de Juiz de Fora - UFJF

Prof $^{\mathrm{a}}$ Marta Corrêa Dalbem UNIGRANRIO

Prof $^{a}$ Mônica Hertz Vice-Decana e Pós-Graduação do CCS 
Todos os direitos reservados. É proibida a reprodução total ou parcial do trabalho sem autorização da universidade, do autor e do orientador.

\section{Denis Luis de Oliveira}

Graduou-se em Administração de Empresas pela Universidade Federal de Juiz de Fora (UFJF) em 2009, tendo sido bolsista do Programa de Incentivo a Inovação em 2008 e bolsista de iniciação científica da FAPEMIG em 2008 e 2009. Especialista em Métodos Estatísticos Computacionais pelo Departamento de Estatística da UFJF em 2009. Trabalhou por dois anos no Núcleo de Pesquisa em Energia e Infraestrutura da PUC-Rio, tendo colaborado em diversos projetos de Pesquisa e Desenvolvimento e em consultorias nas áreas de finanças, opções reais e energia. Atualmente exerce a função de Analista de Mercado na Diferencial Comercializadora de Energia, executando atividades de: acompanhamento do mercado de energia elétrica, previsão de preços, controle interno e avaliação econômico-financeira de projetos.

Ficha Catalográfica

Oliveira, Denis Luis de

Avaliação de projeto de cogeração a partir de biomassa florestal : uma abordagem pela teoria de opções reais / Denis Luis de Oliveira ; orientador: Luiz Eduardo Teixeira Brandão. - 2012. 105 f. : il. (color.) ; $30 \mathrm{~cm}$

Dissertação (mestrado)-Pontifícia Universidade Católica do Rio de Janeiro, Departamento de Administração, 2012.

Inclui bibliografia

1. Administração - Teses. 2. Biomassa. 3. Cogeração. 4. Opções reais. 5. Preço de energia elétrica. 6. Modelo de reversão à média com saltos e sazonalidade. I. Brandão, Luiz Eduardo Teixeira. II. Pontifícia Universidade Católica do Rio de Janeiro. Departamento de Administração. III. Título.

CDD: 658 


\section{Agradecimentos}

Aos meus pais, Vânia Oliveira e José de Arimatéa, que dedicaram a vida pela minha formação e abriram mão de parte dos seus desejos para realizarem meus sonhos. O amor pela família, simplicidade e a disposição de enfrentar novos desafios são valores que aprendi e carrego comigo. Agradeço pelas palavras de incentivo, por estarem sempre presentes e, nos momentos de dificuldade, terem demonstrado calma e segurança nos conselhos. Amo vocês!

À PUC-Rio, pelos auxílios concedidos, sem os quais este trabalho não poderia ter sido realizado.

Ao Prof. Brandão, que já nas primeiras semanas do curso “adotou” um desconhecido e decidiu ajudá-lo. Foram dois anos de intenso trabalho, ricas discussões e muito aprendizado. Sua humildade e busca incessante pelo conhecimento são qualidades a serem seguidas.

Aos meus colegas do NUPEI (Núcleo de Pesquisa em Energia e Infraestrutura), especialmente aos professores Leonardo Gomes, Marta Dalbem, Carlos Bastian e Mario Simões. Agradeço a paciência, as oportunidades e todos os ensinamentos. O carinho e a confiança fizeram de vocês a minha “família carioca”.

A Prof ${ }^{\mathrm{a}}$. Fernanda Perobelli, pelas inúmeras discussões que contribuíram para meu desenvolvimento pessoal e profissional. Sua dedicação e presença serviram de incentivo na escolha do "caminho" das pesquisas.

Aos meus amigos, que durante a semana ajudaram a reduzir a distância de casa e me encorajaram a seguir nesta caminhada. Agradeço aos nossos encontros, sempre marcados por muitas risadas, que geraram experiências inesquecíveis e histórias eternas. Obrigado pela companhia e diversão. Tenho muito orgulho de fazer parte dessa turma.

Por fim, a AES, pela oportunidade de desenvolver o Projeto de Pesquisa e Desenvolvimento e pelo apoio financeiro concedido nestes anos, o que contribuiu para a elaboração desta pesquisa. 


\section{Resumo}

Oliveira, Denis Luis de; Brandão, Luiz Eduardo Teixeira. Avaliação de Projeto de cogeração a partir de Biomassa Florestal: Uma abordagem pela Teoria das Opções Reais. Rio de Janeiro, 2012. 105 p. Dissertação de Mestrado - Departamento de Administração, Pontifícia Universidade Católica do Rio de Janeiro.

A busca por fontes energéticas alternativas tornou-se questão crucial para o desenvolvimento econômico mundial, sendo a biomassa uma alternativa a ser considerada. Neste estudo analisamos o caso de uma indústria de chapas de fibras de madeira, na qual cavacos de madeira podem ser utilizados tanto como matéria prima quanto como combustível para geração de energia térmica. Neste segmento, durante o processo produtivo são gerados grandes volumes de resíduos florestais que podem ser usados como combustível. O objetivo do presente trabalho é determinar a viabilidade econômico-financeira de se instalar um processo de cogeração de energia tendo como combustíveis resíduos florestais e gás natural. Assumimos que os gestores possuem duas alternativas: usar os resíduos e gás na geração de energia, liberando os cavacos para produção de MDF e HDF ou empregar os resíduos florestais, gás natural e cavacos de madeira como combustível, comercializando o excedente de energia no mercado de curto prazo. A avaliação financeira foi baseada na Teoria das Opções Reais considerando a flexibilidade gerencial de selecionar otimamente o destino final dos cavacos de madeira (chapa de madeira ou energia) ao longo do tempo. Uma importante inovação do trabalho consiste na incorporação de fatores de sazonalidade na volatilidade do preço de energia, adaptando o processo estocástico as especificidades do mercado brasileiro. Foi considerada como incerteza o preço da energia (PLD) e adotou-se como base o Modelo Geométrico de Reversão a Média com Saltos de Clewlow, Strickland e Kaminski (2000). Os resultados indicam que a opção de comercializar o excedente de energia não é viável financeiramente e em média não agrega valor ao projeto.

\section{Palavras Chaves}

Biomassa; cogeração; opções reais; preço de energia elétrica; modelo de reversão à média com saltos e sazonalidade. 


\section{Abstract}

Oliveira, Denis Luis de; Brandão, Luiz Eduardo Teixeira (Advisor). Avaliação de Projeto de cogeração a partir de Biomassa Florestal: Uma abordagem pela Teoria das Opções Reais. Rio de Janeiro, 2012. 105 p. MSc. Dissertation - Departamento de Administração, Pontifícia Universidade Católica do Rio de Janeiro.

The search for alternative energy sources has become critical issue for the economic development of the world, and biomass is an alternative to be considered. In this study we analyze the case of a producer of wood fiber boards, in which wood chips may be either used as raw material for the wood boards or as fuel to generate energy. In this segment, the production process generates large volumes of forest residues that can be used as fuel. The objective of this study is to determine the economic feasibility of installing a cogeneration energy process fueled with forest residues and natural gas. We assume that managers have two alternatives: use residues and gas for heat energy generation, releasing the wood chips for the production of MDF and HDF, or use forest residues, gas and wood chips as fuel, selling the surplus energy in the short term market. The valuation was based on the Real Options Theory considering the managerial flexibility to select the optimal final destination of the wood chips (fiber board or energy) along time. One of the innovations of this work is the incorporation of seasonal factors in the energy price volatility, adapting the stochastic process to the specificities of the Brazilian market. The main uncertainty, energy price (PLD), was based on the Mean Reversion Model with Jumps of Clewlow, Strickland and Kaminski (2000). The results indicate that the option to sell the surplus power is not financially viable and on average adds no value to the project.

\section{Keywords}

Biomass; cogeneration; real options; electricity price; model mean reversion with jumps and seasonality. 


\section{Sumário}

1 Introdução 12

$\begin{array}{ll}\text { 1.1. Objetivos } & 15\end{array}$

$\begin{array}{ll}\text { 1.2. Justificativa } & 17\end{array}$

1.3. Estrutura da Dissertação 18

2 Referencial Teórico 20

2.1. Teoria das Opções Reais 20

2.2. Classificação das Opções Reais. 24

2.3. Processos Estocásticos 26

2.3.1. Modelo de Ornstein-Uhlenbeck 28

2.3.2. Modelo 1 de Schwartz (1997) 30

2.3.3. Modelo Misto de Difusão com Saltos 31

2.3.3.1 O modelo de reversão à média com saltos de Clewlow, Strickland e Kaminski (2000) 32

2.3.4. Aplicações de Processos Estocásticos na Modelagem do Preço de Energia 34

2.4. Aplicações da Teoria de Opções Reais no Setor de Energia 40

3 Biomassa na Geração de Energia 43

3.1. Resíduos Florestais e a Cogeração 47

3.2. Potencial do Brasil em gerar Resíduos Florestais 51

4 Setor Elétrico Brasileiro $\quad 55$

4.1. Formação do Preço de Liquidação das Diferenças (PLD) 58

4.1.1. Despacho econômico de geração - Sistemas Térmicos 58

4.1.2. Despacho econômico de geração - Sistemas Hidrotérmicos 60

4.2. Comercialização de energia no mercado brasileiro 63

4.2.1. Ambiente de Contratação Regulado (ACR) 64 
5 Premissas e modelagem da avaliação financeira de um projeto de cogeração de energia.

70

5.1. Investimento 74

5.2. Variáveis que impactam o Fluxo de Caixa 75

5.3. Fluxo de Caixa 77

5.3.1. Fluxo de Caixa Comercialização de Chapas 77

5.3.2. Fluxo de Caixa Comercialização de Energia 77

5.4. Modelagem da Incerteza 78

5.4.1. Série Histórica de PLD - Estatísticas Descritivas 78

5.4.2. Parâmetros do Modelo 80

5.4.3. Fatores de Sazonalidade $\quad 81$

6 Resultados 84

7 Conclusão 92

8 Referências Bibliográficas 95 


\section{Lista de Figuras}

Figura 1 - Eficiência na conversão de energia 49

Figura 2 - Área plantada Eucalyptus e Pinus por Estado 52

Figura 3 - Evolução da área florestal de Eucalyptus e Pinus

das empresas associadas à ABRAF (2000-2010)

Figura 4 - Comparação da produtividade florestal de coníferas e de folhosas no Brasil com outros países 54

Figura 5 - Organograma do Setor Elétrico Brasileiro 57

Figura 6 - Despacho por ordem de mérito e cálculo do CMO 59

Figura 7 - Desafios e decisões de um sistema hidrotérmico 61

Figura 8 - Funções de Custo Imediato, Futuro e o Mínimo Custo Total 61

Figura 9 - Ambientes de contratação de energia e seus agentes 64

Figura 10 - Comparação consumidor Cativo vs Mercado Livre 66

Figura 11 - Etapas do Procedimento de Acesso 68

Figura 12 - Cavaco de Madeira 70

Figura 13 - Processo Produtivo Chapas de Madeira 71

Figura 14 - Fluxo Atual de Produção (sem flexibilidade) 72

Figura 15 - Fluxo Proposto para a Produção (com flexibilidade) 73

Figura 16 - Série Histórica de PLD (Mar/2002 a Dez/2011) 78

Figura 17 - Média e desvio padrão do PLD por período de afluência 79

Figura 18- Efeitos dos Fatores Sazonais na estimação do PLD

Gerador randômico desligado

Figura 19- Efeitos dos Fatores Sazonais na estimação do PLD

Gerador randômico ligado 83

Figura 20 - PLD médio projetado para o período 2012-2021 85

Figura 21 - Valor presente máximo (opção de switch) 86

Figura 22 - Valor presente da Opção (alternativa de comercializar energia) 
Figura 23- Valor presente líquido da Opção

Figura 24 - VPL da opção em função do PLD 88

Figura 25 -Opção vs. Investimento 89

Figura 26 - Número de vezes que a opção foi exercida 89

Figura 27 - Sensibilidade VPL opção 90

Figura 28 - Tornado de Sensibilidade 91 


\section{Lista de Tabelas}

Tabela 1- Comparação entre Opções Financeiras e Opções Reais

Tabela 2 - Processos estocásticos mais utilizados em avaliação de ativos

Tabela 3 - Térmicas no Brasil com combustível de Biomassa

45

Tabela 4 - Percentual Médio de Geração de Resíduos por Indústria 48

Tabela 5 - Número de Agentes inscritos na ANEEL

68

Tabela 6 - Principais características da fábrica (premissas)

Tabela 7 - Investimento necessário para a Cogeração e conexão

à rede

Tabela 8 - Premissas para modelagem financeira

Tabela 9 - Análise mensal da média, desvio padrão e coeficiente de variação do PLD $\quad 80$

Tabela 10 - Parâmetros estimados para o modelo 81

Tabela 11 - Fatores de sazonalidade mensal 82 